\title{
The insider view: tackling disabling practices in higher education institutions
}

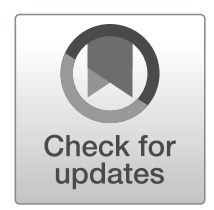

\author{
Wendy Merchant ${ }^{1} \cdot$ Stuart Read $^{2} \cdot$ Stephen $D^{\prime}$ Evelyn $^{3} \cdot$ Caroline Miles $^{4} \cdot$ Val Williams $^{3}$ \\ Published online: 10 December 2019 \\ (C) The Author(s) 2019
}

\begin{abstract}
This paper reports on research about the experiences of disabled staff members in UK universities, drawing on eleven semi-structured interviews with disabled staff in one university, alongside a group auto ethnography conducted by the first four authors, all of whom identified as disabled academics. Disability is generally considered to be predominantly an issue for students, both in practice and in the literature. By contrast, taking a social practice approach, we focused on the barriers faced by disabled employees, both overt and hidden. We found that disability was still viewed as a medical problem, and that disabled members of staff faced considerable extra labour in organising their own supports. We were often made to feel that we were unwanted and that we were 'misfits' in the institution. This paper contributes to theory by showing how social practices can become exclusionary, and how interconnections between practices matter. We discuss ways in which ableism, based on the ideal of 'individual' excellence, creates barriers for disabled staff. In the global context of Higher Education, the increasing marketization of universities in higher income countries creates a difficult climate for the values of inclusion.
\end{abstract}

Key words Disability · British Higher Education · diversity · equality · social practices

\section{Introduction}

This paper aims to analyse the practices which constitute barriers for disabled staff in one UK university, with the wider goal of situating our analysis within the global context of higher education in a changing world. We write from a critical perspective, informed by debates in

Val Williams

val.williams@bristol.ac.uk

1 Independent Researcher, Bristol, UK

2 Bath Spa University, Newton Saint Loe, UK

3 University of Bristol, Bristol, UK

4 West of England Centre for Inclusive Living, Bristol, UK 
Disability Studies. Our aim is thus more ideological than merely practical, although it is based on the fundamental principle that real change comes from changing practices even more than changing policy. As opposed to the taken-for-granted view of disability as illness, scholars such as Oliver (1990), Shakespeare (2014), Thomas (2004) and Garland-Thomson (2011) are in various ways more concerned about the societal forces shaping disabled people's lives. As in our previous work (Williams et al. 2018), we are particularly interested to explore how disabling barriers are experienced, and can be described and understood as social practices (Shove et al. 2012; Reckwitz 2002). Thus, our disability focus moves beyond the individual, and has much in common with a social relational view of disability (Thomas 2004), exploring the normative ways in which society shapes disabled people as 'other'.

We are concerned here with the practices and structures of universities, since the university sector is a key societal context for generating and disseminating new knowledge, and we maintain that a truly 'inclusive' academia should be reflected both in the learners and in the staff of the institution. Unfortunately, as we shall see, 'ableism' (Dolmage 2017) or 'biomeritocracy' (Taylor and Shallish 2019) are invisibly threaded through universities, even when the institution has an overtly inclusive policy (Titchkosky 2008). Nevertheless, if there is a will to change, then we need to know how to recognise, analyse and change interconnected practices which are shaped, often unwittingly, by the demands of the institution. Disability is formulated and experienced differently in particular contexts and circumstances (Mellifont et al. 2019) and so, as argued by relative interactionists (Gustavsson 2004), an analysis of social practices must also be sensitive to the 'complexities of the body's constant and transformative interaction with the social' (Taylor and Shallish 2019, p. 4).

UK universities such as the one in this study regularly frame themselves as international institutions, welcoming students and staff from across the world. Thus, disability inclusion relates not only to those from UK backgrounds, but also to people whose background and ideas about disability may have been formed in very different circumstances. Figures from the Higher Education Statistics Agency (2018) suggest that approximately $4.1 \%$ of academic staff and $5.8 \%$ of non-academic staff in universities self-identified, or declared, as disabled in the academic year 2016/17. As Brown and Leigh (2018) point out, this represents a 'stark under-representation of disabilities, chronic conditions, invisible illnesses and neurodiversity amongst academic staff' (p. 985), given that approximately 15$16 \%$ of the overall UK adult population are estimated to have a disability. Yet higher education policy in the UK has strongly emphasised both the 'widening participation' agenda for students, as well as increasing diversity amongst staff. In the UK, the Equality Act 2010 and the accompanying Public Sector Equality Duty, legally requires educational institutions to provide 'reasonable adjustments' with the overall goal to eliminate discrimination, advance equality of opportunity and foster good relations between disabled and non-disabled people. Pertinently for this paper, that includes of course, disabled people who apply or who hold posts as members of staff. However, as Baltaru (2019) argues from a recent policy analysis, each Higher Education Institution (HEI) has interpreted these requirements in different ways, with its own set of policies and procedures. Nearly all HEIs in the UK have equality officers, and keep statistics to monitor equality issues amongst staff and students, with the HEI in this paper reporting in 2016/17 that 5\% of their staff had declared a disability. The vision of the HEI in question included in 2016 a statement that: 'We aspire to a fully inclusive culture'. It is in this context of policy aspiration that we turn in this paper to an exploration of the experience of that inclusive culture from the perspective of disabled staff. 


\section{Theoretical background}

This paper develops and tests the theoretical lens shaped in a wider study of disabling barriers and change (Williams et al. 2018), in which we sought to show through examples of data, and patterns in the data, how exclusion happens, and how it can be reversed. The present paper thus seeks to take forward a set of ideas with wide applicability. Disability Studies in the UK claimed that the unthinking 'interventionist' approach of research about disability is part of the oppression disabled people face (Oliver 1992). By contrast, Disability Studies has always prioritised close, first-person accounts of disability by disabled people themselves (Swain and French 2000). Disability Studies has also relied heavily on a distinction between social and medical approaches to disability, although that binary distinction has been critiqued repeatedly, with Thomas (2004) for instance, showing how medical sociology and Disability Studies tend to coalesce around a 'social relational model'. In the context of higher education, both learners and academics may be disabled both by their own impairments, but also by the interaction between those impairments and the context of their goals in academia. Thus, a relative, or 'interactionist' view of disability (Gustavsson 2004) is the most productive starting point for this paper, where impairment effects as well as social barriers can be recognised.

In our quest to understand better how disabled people fare in universities, we became interested in social practice theories (Williams et al. 2018), as they offer tools for questioning the 'status quo'. Instead of focusing on the behaviour of individuals, they turn the gaze towards the ways in which practices or patterns can endure 'between and across specific moments of enactment' (Shove et al. 2012, p. 7). As Schatzki (2001) puts it, these patterns are recognisable, structured and ordered, and so social practice theories form a useful theoretical bridge between the personal and the wider, structural properties of society. However, practices can become stuck in both helpful and unhelpful ways, and so the need to change and shift practices is also a key goal of theorists. Each time a social practice (such as, in this case, teaching or researching in a university) is enacted, there is the potential to reconfigure and 'unstick' the practice.

Shove et al. (2012) offer a simple, practical framework of 'elements' from which specific practices are composed, suggesting that any social practice is made up of values, human competences and material 'things'. Each of these three elements can provide a way to understanding how a practice is shaped, and how it could be re-shaped. For example, in UK universities, 'being research intensive' is often considered a core value, and academic staff are required to produce research papers. The practice of writing up research, however, invariably results in bulges of time spent at unsociable hours and using the material technology one has in one's own home, in order to meet deadlines or respond to peer review. All this could be said to draw on and expand the competences of academics. However, there are considerable difficulties associated with this array of practices, which impact particularly on disabled members of staff. If research excellence is to be demonstrated, one needs both the time and opportunity to nurture and display that excellence, commodities which might be in short supply if one's private life is facilitated by supporters or carers, if a disabled person is also a carer, or if the technology one needs is not available. We see here immediately the messy, ill-fitting jigsaw of impairment, personal adaptations and institutional practices, where disability can be seen as relative both to the person and to the situation. Hui (2017) starts to outline some of the complexity in the interconnection between different practices, and Williams et al. (2018), drawing on Blue and Spurling (2017) and Schatzki (2017), have emphasised the embedded nature of practices, and the complex ways in which interconnections can become exclusionary for disabled people. 
Social practice theories in general have not always focused on the possibility of disruption and change, although Shove et al. (2012) open with the hopeful statement that 'theories of practice have as yet untapped potential for understanding change' (p.1), including in areas of inequality, and Watson (2017) has argued that the concept of power needs to be central to social practice theory. As in our previous arguments (Williams et al. 2018), we specifically consider how social practices act to include or exclude certain groups of social actors. As Hui (2017) suggests, groups or communities (categories of people) can be created by their positioning in practices, and these categories then become meaningful ways of excluding or including them in other, linked practices; for instance, the categorisation of people as deserving of public welfare or social care, which might then make them unlikely candidates for professional employment. Even when they are successful in gaining employment in a university, disabled staff members can face practices such as selection, review and promotion, which may still militate against them.

Disability scholars such as Titchkosky (2008) and Garland-Thomson (2014) have taken these ideas further, by offering personal accounts of their experiences as disabled academics, with an eye to revealing and disrupting practices in which disabled people are excluded. Moreover, Mellifont et al. (2019) conducted a systematic review, analysing sixteen papers, almost all from high-income countries, which contained autobiographical narratives by disabled academics. Similarly, we draw on concepts such as ableism, the processes by which universities define and perpetuate what counts as 'valued' in a society (Dolmage 2017), recognising that ableism is generally 'dysconscious', a term used by Broderick and Lalvani (2017, p. 895):

"an impaired or distorted way of thinking about dis/ability (particularly when compared to criticalist conceptualisations of dis/ability), one that tacitly accepts dominant ableist norms and privileges".

Disability is seen differently across the world, and may in some cultures simply equate with a negative lack of ability to cope. Berghs (2015) rightly points out that people are unlikely to identify as disabled if the term implies they are unable to cope in situations of hardship, such as conflict or migration. In the context of disability in higher education, the vast majority of the research draws on universities in higher income countries. From what is known, however (Tudzi et al. 2017; Mutanga 2018), those in the Global South face very different material disadvantages which will likely affect accessibility, as well as discriminatory attitudes with regard to disability. Dolmage (2017) claims that ableism is a universal phenomenon, and we will return to the global reach of this concept and how it interacts with social practice theories in the final 'Discussion' section of this paper.

The paper is shaped by its theoretical aims, and is organised in the following way. First, we review briefly the literature about disability in universities. We then give some details of the research which formed the basis for this paper, before presenting a 'Findings' section which discusses key themes which have a bearing on the arguments about social practices. We structure the Findings according to practices which are undertaken by academic staff in universities, such as entering the higher education sector, and reflect on those messages in the final Discussion section, in order to consider both the policy and theoretical implications.

\section{Disability in Higher Education}

The vast majority of writing about disability and the academy centres on the experiences of disabled students (Berggren et al. 2016; Cameron 2016; Collins et al. 2019; Lourens and 
Swartz 2016). There is also a whole body of literature about identity and 'disclosure' of disability in higher education (Blockmans 2015; Cunnah 2015), and some of this work is led by disabled students themselves (Griful-Freixenet et al. 2017; Blockmans 2015), or centres on their voices. For instance, Girli et al. (2016) report on discrimination faced by disabled students in Turkey; Mutanga (2018) similarly starts from new policy imperatives in South Africa, which promote inclusion, to question the discriminatory practices which create negative experiences for disabled students; and Tudzi et al. (2017) report on a survey of 53 disabled students in Ghana, showing how the built environment remains inaccessible to them.

In our own research, we have also found that the term 'disability' (both in official university policy and in everyday practice) is automatically associated with students, revealing the tacit assumption that staff working in higher education cannot be 'disabled' (Williams et al. 2018) (although for an exception, see Williams and Mavin 2015). This lack of attention to disability in academia makes visible some uncritical and dominant norms in institutional thinking about 'disability' and its relationship with the tasks of learning and teaching. Dolmage (2017) and Taylor and Shallish (2019) go further by discussing how disability has traditionally been studied in universities, situating disabled people as objects - and in fact, as problematic objects to be cured, rehabilitated or removed from view. Far from the inclusive idea of emancipatory knowledge (Freire 1970), where the task of education is associated with raising consciousness, this attitude towards disability reveals some disturbingly conservative ideas both about disability rights, and about the positioning of 'object' and 'agent' of knowledge.

The term 'disability' is still sometimes equated with a lack of ability to gain senior positions in employment (Hansen 2008; Roulstone and Williams 2014), and nowhere is this more so than in universities, where the 'hierarchies in higher education [are] based on the pervasive construct of normalcy' (Taylor and Shallish 2019, p. 2). Power structures are endemic in most organisations, but in universities, the elite status of a senior academic may be combined with the power of management, and power can play out in subtle ways (Fleming and Sturdy 2009; Hancock and Tyler 2009). The various forms of organisational control can be seen in the seemingly mundane and 'ordinary' current practices in the university sector, where academics in particular are under pressure to promote their individual careers, as well as to be loyal to the overall goals of the institution (Mills et al. 2014). More generally, in the USA and UK at least, the marketisation of higher education (Cribb and Gewirtz 2013; Martin 2016) creates a targetdriven culture where departments rely on their ability to recruit students, to gain high scores on 'student satisfaction', and simultaneously to produce academic papers which are graded by panels of 'experts' in order to reward those institutions where research excellence is demonstrable. In that culture of commodification, it is maybe unsurprising that the experiences of disabled staff within universities have generally been shown by research to be problematic (Brewster et al. 2017; Brown and Leigh 2018; Corlett and Williams 2011; Inckle 2018; Waterfield et al. 2018; Williams 2011). Despite some positive 'coping strategies' reported, a dominant theme is the normative 'ableism' which is embedded unconsciously in the academy, from recruitment practices (Chan 2005) to physical access (Titchkosky 2008), and the pressure placed on disabled academics (Raymaker 2017).

Another dominant theme in this literature is that there are often gaps between overt policies and the practices which are experienced by members of an institution. Universities may also have a powerful market-driven incentive to appear to be 'free thinking', valuing new ways of engaging with social realities, and above all, wishing to develop their profile with the whole community, including those who might be marginalised (Facer and Enright 2016). Therefore, as mentioned above, the 'equality and diversity' agenda is very prominent in most UK 
universities. However, as we shall see in this paper, that does not necessarily translate into management of the workforce in ways that promote innovation (Findlow 2008).

In summary, we know that disabled staff face additional labour, as well as barriers to career survival and progression, and that in universities this can be compounded by institutional drivers. In this paper, we will explore how staff members in one UK university experience higher education practices, how those practices are connected and constituted, and how they impact on the personal experiences of being disabled in academia.

\section{Method}

The data on which this paper draws comes from a three-year programme of research funded by the Economic and Social Science Research Council in the UK, in which one project investigated disabled people's experiences, both as students and staff, within a university. Both parts of this project were led by disabled researchers themselves, with a co-research group formed of nine disabled students, and disabled academics leading the research about staff experiences. The method was action-oriented (Reason 1994) aiming to create change and reflect on those changes.

The first four authors of this paper were all staff members who identified as disabled, and we undertook our own inquiry, with the aim of sharing and analysing our own experiences. We have debated about how to describe our methodology, which developed as the project progressed: we initially set out to carry out a group narrative inquiry, alongside that of the student researchers, which would enable us to appreciate how our identities and experiences are connected with the social and cultural practices around us (Trahar 2013, p. xx1). For the students, that method culminated in detailed self-narratives, which were shared amongst the group, and resulted in a piece of collective writing based on their reflections (Getting Things Changed 2018). Members of the disabled staff team by contrast chose to share their experiences via individual interviews carried out by the first author, supplemented by group discussions, held on a monthly basis through the course of the project. The first author did not supply an individual interview, but instead contributed to a composite narrative. All this gave us a safe, confidential space to explore our feelings and issues, and to reflect on the personal nature of our issues in the broader context of social barriers, while we discussed and developed theories about social practices. Our method thus had some of the key characteristics of a collaborative auto-ethnography, which are usefully set out by Wall (2006), with the opportunity for each of us to use our own experience as a source of reflection. However, as Wall (2006, p. 155) admits, this very individualised method runs the risk of being criticised as 'self-indulgent, narcissistic, introspective'. Set within the wider forum of discussion and group analysis, we were able to draw out the key themes which bound us together, while reflecting on the differences amongst us and what these all revealed about disabling and enabling practices in universities.

This article draws primarily on the interviews conducted with participants other than the authors, and is interpreted and validated via our own experiences. Individual interviews were carried out by the first author, with six other members of staff identifying as disabled, two of whom additionally supplied written narrative accounts. One additional participant chose to supply her own written narrative instead of a verbal interview, resulting in a total of three written narratives. Details of all participants, including ourselves, are given in Table 1, although we have deliberately avoided being explicit about individuals to maintain anonymity. Altogether, including the authors, there are thus eleven people's experiences represented in this 
paper, six female and five male, five of whom had 'visible' disabilities, and six whose primary disability was non-visible. Most were academic members of staff, although only two had permanent roles, both with teaching as a priority. All the others had contracts linked to particular research projects, and all were broadly speaking working within the social sciences, where awareness of disability issues might be assumed to be higher than in the hard sciences. Thus while we do not have data, the experiences of disabled academics in other disciplines might be yet more problematic.

The interview schedule was open-ended and non-structured, since we wished to allow the participants maximum freedom to describe their experiences in their own way. All interviews were conducted by the first author, who self-identified as 'disabled' towards the start of the interview. It should be noted therefore that, in line with our theoretical aims, we do not claim that our data set is 'neutral', but is meant to be a means of probing the complexity of disabling barriers faced by both the interviewer and interviewee, via peer interviewing (Williams 2019). Sharing and involving each other in meaning making was one way of managing the relational ethics outlined by Ellis (2007) in relation to analysing auto-ethnographies.

Prompt questions were included on these areas:

- Personal background and job at the university

- Accessing the university facilities

- Any interactions with professional services, such as Human Resources.

- Participants' goals in the workplace

- Support and adaptations, and how these were accessed.

The three written narratives, along with the transcriptions of interviews, were entered into NVivo for thematic coding and analysis. This was done by focusing on 'process coding' (Saldaña 2015) which was carried out with a view to revealing how social practices in universities were constituted within wider values and hidden norms. For instance, where a theme emerged about being 'shut out' or not valued, this was linked with the seemingly mundane practice which had engendered these feelings, such as the ways in which teaching rooms were allocated and timetabled. Inevitably, that process involves an analytical jump from experience to process, but can be very useful in making the shift to understanding how a practice can be changed. In the Findings section below, these process codes were combined into overarching, higher level activities. The majority of the data fell within the temporal frame of: a) 'starting to work in a university'; b) 'managing the extra labour of being disabled'; and c) 'getting to the threshold of doing the job', which includes the accumulated barriers we have all faced to promotion and progression in the university sector.

Table 1 Details of participants represented in this paper

\begin{tabular}{llll}
\hline Nature of disability & Gender & Ethnicity & Role and discipline \\
\hline Visible & Female: 3 & White UK: 4 & Academic roles: \\
& Male: 2 & Other White: 1 & Social policy: 3 \\
& & & Social medicine: 1 \\
& & & Professional services: 1 \\
Non visible & Female: 3 & White UK: 5 & Academic roles: \\
& Male: 3 & European: 1 & Social policy: 3 \\
& & & Professional services: 2 \\
& & & Economics: 1 \\
\hline
\end{tabular}




\section{Findings}

\section{Starting to work in a university}

The majority of participants in this study had 'informal' or relatively casual introductions to the university. UK universities tend to offer their research students the opportunity to carry out small amounts of teaching, and thus some of our participants had experienced a gradual 'slide' into becoming part of the academy, while others, including the authors of this article, had shifted between academia and disability activism. More conventionally, others had arrived for their job interviews without disclosing or discussing their disability. One person said they were advised by doctoral supervisors not to disclose their disability when applying for posts for fear of discrimination.

In terms of access to reasonable adjustments or accommodations, there was a lack of transparency and openness which permeated the recruitment process. As the member of staff settled into their job, a certain informality in the way tasks accumulated did not necessarily serve them well:

"I didn't know who to ask for it, because there was - again, it was on a casual basis; my supervisor said, 'Do you want to do some teaching?' - 'Yes', and that was it. There was no going through HR or anything like that, that might have triggered some of those processes." (005)

The UK has an "Access to Work" scheme, which is intended to ease the work situation for any disabled employee (Department for Work and Pensions [DWP] n.d.), but many participants had no experience or conception that they had a right to financial or material supports. One person reported that they were not told about Access to Work by the university until they had been in employment for their first year, a point at which the university's probation system could have meant them failing their initial service review period and quite legally having their contract terminated. Thus, the concept of meritocracy was built into and acted as a justification for legal processes, trumping the concept of right to adaptations. Another participant reported how:

"there was no support from the university around applying to Access to Work. It's kind of like, you're disabled, this pot of money is here; apply for it. You're on your own. Go.” (004)

If the university became involved in providing support, this was potentially because of a disabled member of staff experiencing some type of crisis. Often, participants who had experienced these situations were referred to occupational health services, another practice which was very familiar to the authors. While these interactions were mostly found to be useful, participants felt there was a lack of understanding and sensitivity around disability and the difficulties that disabled staff experienced. As one participant demonstrated, as a person with an invisible disability, the interaction with occupational health services made them feel that they personally needed to change. Such an approach therefore assumed a medical model of disability, rather than a consideration of the disabling environment in a university, as we shall take up later in the Discussion.

"It was just awful, being told you've got to be healthier. That's just ... it's an impossible challenge. And what person wouldn't want to be healthier? Stupid thing. Stupid". (011)

The very essence of a HEI is brought clearly into light via the exploration of these accounts, and by our own shared narratives. The response to any perceived deviation from the norm is to 
create a structure within the institution to smooth over the crack, and to ensure that 'normal service' is resumed. Lack of health is equated with disability, and abilities are seen as 'natural outcomes of biology' (Taylor and Shallish 2019, p. 6). Further, the individual is assumed to be the source of the problem, containing elements that can be remediated. No wonder then that participants spoke about their intense isolation, feeling that they had to manage alone, in order to prove themselves in this competitive environment.

\section{Managing the extra labour of being disabled}

Disabled staff members in the university identified that far from being considered positive contributors, they frequently struggled with disabling experiences that emanated from the difficult and individualising 'support' processes we have described above. For instance, a direct consequence of the individualised notion of Access to Work was that we as disabled members of staff incurred extra labour. This labour included managing the timesheets of support workers, submitting monthly claims both to Access to Work and to the university, and dealing with lengthy queries from the DWP. One disabled staff member in our interviews suggested that:

“...I spend about three days a week - three full-time days a week - arranging my own travel, booking it all, researching it, filing my university claims - because everything has to be claimed through the university first - and then the Access to Work claim. Each one is a three-stage process..." (003)

Another reported that their application to Access to Work was still being processed after two years. Participants described having to not just invest additional labour in managing additional support processes, but also time and energy in navigating bureaucratic issues and unexpected challenges.

Alongside these practical tasks co-exists the work that disabled staff had to undertake in order to physically negotiate their place in the university. For example, one participant described how non-disabled individuals would sometimes park in his disabled car parking bay, which effectively blocked him from parking his car, and therefore, made it difficult for him to access the building he worked in. Each time this happened, he was required to invest additional labour to challenge the driver:

"I have been told that if that happens again, we can call security. But ... the fact is that somebody should be telling the people parking in that space, they have to park somewhere else..." (007)

Material barriers were matched by the need to challenge negative attitudes towards impairments voiced by colleagues, who in one case questioned whether an academic could be someone who experienced mental health issues. Invisible disabilities led to some complexity in how this particular member of staff viewed herself and was viewed by others. This participant worked and taught students to prepare for the caring professions, and so the unthinking denigration of someone with mental health issues only serves to reinforce society's view that such people are not 'fit' to become caring professionals:

"When this issue has happened, it, again, puts all sorts of doubts in my mind. ...am I deserving of being in the ... profession? Go back to, am I a fraud, lecturing ... when 
actually I may not even be deserving of being in the ... profession? ... I think I have become much better at saying, this is his or her problem, not mine. And actually it's a sign of ignorance...” (002)

\section{Surmounting ableist barriers in getting to the threshold of doing the job}

Throughout the interviews, people talked of faceless bureaucracy and 'the system' of the university, and how university structures and procedures were rigid and unsupportive of the holistic needs of disabled staff. As one participant commented:

"It's so many different bits of the university, spread out everywhere, where no one none of these different factions seem to talk to each other. So occupational health may talk to HR by sending them the report, but then how does that then feed back into your own department? Estates? Parking? Facilities? All these different things.” (004)

An example of these disconnected university structures was reflected in the experiences of disabled staff attempting to attend conferences, meetings or do field work in other parts of the country, including for instance the conference from which the current paper was developed. While such activities may be 'normal practice' in an academic schedule, and indeed essential for networking and career development (Williams and Mavin 2015), managing these obligations was a challenging experience for disabled staff. One participant in the current research reported at length how the pre-booking of rail transport as a wheelchair user, and the personal financial cost of this, conflicted with the booking system in place at the university. This participant also experienced similar difficulties in sourcing accessible accommodation, as well as ensuring accessibility at the conference itself.

These material barriers might seem to have little to do with academic 'meritocracy'. Yet the connections between the material and the individual academic career are very tight, with the material barriers reflecting the lack of value afforded to celebrating disability as an asset. If an individual cannot easily attend a conference, or has to spend extra time and labour simply organising access to a building, then there is little time left for the production of high-quality research outputs. Disabled members of staff had to organise their own solutions. For those who were teaching, one participant set out in detail how when preparing for their new teaching contract, they requested the timetable before the start of the academic year, so that they could visit all the rooms to ensure they knew the route, and had anticipated any possible problems. However, another participant, with a visual impairment, continued to experience problems in finding his way in old, complex, winding buildings, especially when he wanted to visit a colleague's office. He noted that while his colleagues helped out, he felt that this friendly support was almost 'bucking the system' and certainly was not recognised by the university:

"How about a map, so I can find my way around to offices, you know, because many of the offices aren't clearly labelled, and he did that. So it was all very ad hoc, on the fly, very custom-built, without involving any of the university systems, whatever they were. It was all handled on a local basis." (005)

At times, the rigidity and lack of recognition of their rights caused deep and raw feelings from participants. For instance, during the course of the research, the university proposed the 
introduction of car parking charges for all members of staff. One of the major actions taken by our team related to challenging and successfully halting this proposal. It revealed a basic lack of understanding that many disabled people will have no choice about their mode of transport, already have an array of disability-related extra costs, and need a parking space close to work in order to do their job. One participant summed up:

"My feeling was there was no representation whatsoever of disabled staff on campus.

Not even on their radar, really". (004)

All employees have to get to their workplace, to organise their timetable, to find rooms and to meet with colleagues. These issues may seem to be routine and mundane, and have nothing to do with the exclusionary forces at play in the higher education system. However, these social practices only become problematic - and therefore noticeable - when they exclude disabled people. Our participants, and several in our own team, were often forced to reflect that they 'misfitted' the academy, and that it was not a place for them.

Academic career pathways for disabled staff are still very tenuous, and nowhere is this more visible than in the practices relating to publication. As the current paper has been re-drafted, most of the team has moved on, and only one of the current authors still has an academic post. Ableism shapes two intersecting aspects of this exclusion of disabled academics, as we ourselves have variously experienced. One is that we find ourselves not wanting to remain in academia, due to the frustrations outlined in this paper. The second is that we find ourselves not able to remain, since promotion and application processes have relied on a concept of individual meritocracy, unrelated to the realities of our working lives. It should also be noted that in writing and submitting this paper we have drawn on the availability of the fifth author, who is a retired professor, not identifying as disabled and not subject to the same ableist exclusion. Academic progression, recognition and publication thus are all revealed as complex, interlinking and ableist practices embedded in our own team work.

\section{Discussion}

This paper has sought to understand the experiences of disabled university staff through exploring the social practices in one UK university. Our findings related overwhelmingly to social practices involving physical resources and structural adjustments, and the difficulties faced by unseen disjunctions between practices, such as the Access to Work scheme and the University funding and procurement systems. The wider disabling meritocracy built into higher education was made visible for us via the material and the particular. What was evident from our data was that the support needed by disabled employees was primarily about the infrastructure of people and the mundane physical environment of the university - the enablers to get to the threshold of doing their job - not about their actual skills to do the job. Unfortunately, as several participants pointed out, they became 'misfits' (Garland-Thomson 2011) before even getting through the door.

The closed door to the academy therefore took on both a metaphorical and literal meaning to disabled participants in this study. However, the inaccessibility of many buildings in this university cannot be simply understood as a problem of resource and materials, since a commonly heard discourse about access related to the aesthetic status of old buildings, which in some cases had a degree of environmental protection. Thus, the value and meaning 
associated with accessibility appear to be trumped by the value of a beautiful and historic building, sometimes seen as a way of attracting students. The elements of material 'things' such as doors, corridors, signage and parking (all matters which concerned our participants) were thus inextricably bound to and shaped by elements of meaning and value (Shove et al. 2012); the university is created as an ancient seat of learning, rather than as an inclusive environment.

Both the internal elements of a practice, and the interconnections between practices (Hui 2017), seemed to be at the root of experiences for university staff. These operated differently according to the individual, to the discipline in which they worked, and to their impairment, thus linking social practice theories (Shove et al. 2012) very usefully with relative, interactionist theories of disability (Thomas 2004). Not all the participants had visible, or physical disabilities (see Table 1), although 'visibility' was often a fuzzy concept, linked to the extent to which a disability was made relevant by the person themselves and by others around them. Turning back to our Findings, for instance, a visual impairment might not be immediately obvious to others, but in the case of one participant, colleagues were keen to support and to enable the individual to manage the environment, thus acknowledging the impairment in an informal and collegial way.

In more formal terms, the physical resources necessary to do one's job surfaced in accounts of the equipment or IT a disabled person might need to access information, to communicate, or to use a computer. In the UK, these are obtainable via the Access to Work scheme, although as we saw above, there were constant uncertainties because of failures to obtain expert advice, and long delays and additional administrative layers added by the HEI. Ironically, the practices associated with Access to Work are precisely the 'reasonable adjustments' required of public institutions under the UK Equality Duty. However, as this paper has revealed, 'reasonable adjustments' tend to single out the individual as different, without fundamentally changing the whole practice. Taylor and Shallish (2019) outline that problem in relation to students, but we found it just as true for disabled staff.

At the heart of these problems lies the not-so-hidden, and global, assumption of selfreliance. Internationally, the academic system is one which rewards 'excellence', which is construed as a biological property, a 'given' fact related to the individual member of staff. Just as the journey in academia is charted via research outputs and contributions attributed to an individual, via staff review processes and promotion procedures, so also is a disabled member of staff expected to self-manage and make invisible the extra labour caused by the need to adjust and to create access for themselves. In other words, participants' experiences described having to show academic excellence, 'despite' their disabilities. Thus participants, such as those with visual impairments or who used wheelchairs, reported having to spend time checking out the route to the lecture theatre and the accessibility of the lecturing platform, and IT. This additional labour of course can be simply the unseen precursor to the preparation and delivery of a lecture that has to meet the high standards and needs of students, and will be reflected in national student surveys. One can appreciate here how the minutiae of material experiences are driven by the wider goals of the university to succeed in a competitive environment, where (in the UK) student ratings are used as the basis of university rankings.

It should be stressed that the problems unearthed in our research are not uniquely associated with one university, and as far as can be seen from the literature (Taylor and Shallish 2019; Mellifont et al. 2019), these are universal issues which pervade the culture of higher education, certainly in countries with higher economic status. The global power accorded to universities in the UK, North America and Australia, for instance, is expressed in publicity which creates 
the 'global institution', attracting international students and leading knowledge transfer throughout the world. Where universities lack the humility to create equal paths for dialogue with lower income countries, this stance has been critiqued as a type of neo-colonialism (Meekosha 2011; Cutajar and Adjoe 2016). Further, as we have described, the assumption of individual excellence is never far from the surface of university discourses, and is associated with self-reliance. Collaboration or team efforts, which may be particularly beneficial for disabled staff, do not figure so highly within academic promotion procedures as do publications and grant income. In that context, it is hard to see how a university's practices and vision could really match the goals of inclusivity, since these in some respects compete with the business-like stance of university management and decisions (Cribb and Gewirtz 2013). Thus, we would argue that change will only occur via a values-based move towards an understanding of inclusivity as a key and important part of society, an essential ethical core of diversity and humanity, which should be at the heart of any knowledge exchange and discovery.

Changes thus have to be made firstly by confronting and recognising the values underpinning higher education. This cannot be achieved by a simplistic 'tick box' approach. Our own university is enthusiastic to make changes, and has incorporated some of our research findings, specifically those which relate to concrete 'access' issues to be assimilated into new building plans. However, of the three elements of Social Practice theory, which Shove et al. (2012) suggested, we argue that a change in values is necessary in order to change the competences and material resources of inclusivity in universities. Further, our conclusion is that the presence and participation of particular groups of social actors do matter (Hui 2017): value shifts will only occur once disabled staff are present in higher education and in policy arenas, and in senior positions. The presence and inclusion of new social actors in itself can create the conditions for change.

Acknowledgements Thanks are due to all participants whose views and experiences helped to shape this paper, and also to the university itself for agreeing to the research. We also gratefully acknowledge the support given to this paper by Professor Andrew Sturdy at the University of Bristol. Most of all, we recognise the unique contribution of Dr. Sue Porter, who died suddenly early in 2017, and whose experience of disability and academia inspired us to continue with this project.

Funding Information This research was supported by a grant from the Economic and Social Research Council (ESRC) ES/M008339/1 (Tackling Disabling Practices: co-production and change).

Data reported in this paper is part of a data set deposited (31/08/2018) with the UK Research Data Service. Details are not yet available.

Open Access This article is distributed under the terms of the Creative Commons Attribution 4.0 International License (http://creativecommons.org/licenses/by/4.0/), which permits unrestricted use, distribution, and reproduction in any medium, provided you give appropriate credit to the original author(s) and the source, provide a link to the Creative Commons license, and indicate if changes were made.

\section{References}

Baltaru, R.-D. (2019). Universities' pursuit of inclusion and its effects on professional staff: The case of the United Kingdom. Higher Education, 77(4), 641-656.

Berggren, U. J., Rowan, D., Bergbäck, E., \& Blomberg, B. (2016). Disabled students' experiences of higher education in Sweden, the Czech Republic, and the United States - A comparative institutional analysis. Disability \& Society, 31(3), 339-356.

Berghs, M. (2015). Radicalising 'disability' in conflict and post-conflict situations. Disability \& Society, 30(5), 743-758.

Blockmans, I. (2015). "Not wishing to be the white rhino in the crowd": Disability-disclosure at university. Journal of Language and Social Psychology, 34(2), 158-180. 
Blue, S., \& Spurling, N. (2017). Qualities of connective tissue in hospital life: How complexes of practices change. In A. Hui, T. Schatzki, \& E. Shove (Eds.), The nexus of practices: Connections, constellations, practitioners (pp. 24-37). Oxford: Routledge.

Brewster, S., Duncan, N., Emir, M., \& Clifford, A. (2017). Personal sacrifice and corporate cultures: Career progression for disabled staff in higher education. Disability \& Society, 32(7), 1027-1042.

Broderick, A., \& Lalvani, P. (2017). Dysconscious ableism: Toward a liberatory praxis in teacher education. International Journal of Inclusive Education, 21(9), 894-905.

Brown, N., \& Leigh, J. (2018). Ableism in academia: Where are the disabled and ill academics? Disability \& Society, 33(6), 985-989.

Cameron, H. E. (2016). Beyond cognitive deficit: The everyday lived experience of dyslexic students at university. Disability \& Society, 31(2), 223-239.

Chan, A. (2005). Policy discourses and changing practice: Diversity and the university-college. Higher Education, 50(1), 129-157.

Collins, A., Azmat, F., \& Rentschler, R. (2019). "Bringing everyone on the same journey": Revisiting inclusion in higher education. Studies in Higher Education, 44(8), 1475-1487.

Corlett, S., \& Williams, J. (2011). The effects of discourse and local organizing practices on disabled academics' identities. Paper presented at the 7th International Critical Management Studies Conference, 11-13 July 2011, Naples: Italy.

Cribb, A., \& Gewirtz, S. (2013). The hollowed-out university? A critical analysis of changing institutional and academic norms in UK higher education. Discourse: Studies in the Cultural Politics of Education, 34(3), 338-350.

Cunnah, W. (2015). Disabled students: Identity, inclusion and work-based placements. Disability \& Society, $30(2), 213-226$.

Cutajar, J., \& Adjoe, C. (2016). Whose knowledge, whose voice? Power, agency and resistance in Disability Studies for the Global South. In S. Grech \& K. Soldatic (Eds.), Disability in the Global South: The critical handbook (pp. 503-516). London: Springer.

Department for Work and Pensions [DWP] (n.d.). Get support in work if you have a disability or health condition (Access to Work). https://www.gov.uk/access-to-work. Accessed 30 Oct 2019.

Dolmage, J. T. (2017). Academic ableism: Disability and higher education. California: University of Michigan Press.

Ellis, C. (2007). Telling secrets, revealing lives: Relational ethics in research with intimate others. Qualitative Inquiry, 13(1), 3-29.

Equality Act (2010). The Stationery Office, London, UK.

Facer, K., \& Enright, B. (2016). Creating living knowledge: The Connected Communities Programme, community-university relationships and the participatory turn in the production of knowledge. University of Bristol: Arts and Humanities Research Council.

Findlow, S. (2008). Accountability and innovation in higher education: A disabling tension? Studies in Higher Education, 33(3), 313-329.

Fleming, P., \& Sturdy, A. (2009). "Just be yourself!": Towards neo-normative control in organisations? Employee Relations, 31(6), 569-583.

Freire, P. (1970). Pedagogy of the oppressed. New York: Herder \& Herder.

Garland-Thomson, R. (2011). Misfits: A feminist materialist disability concept. Hypatia, 26(3), 591-609.

Garland-Thomson, R. (2014). The story of my work: How I became disabled. Disability Studies Quarterly, 34(2). https://doi.org/10.18061/dsq.v34i2.4254.

Getting Things Changed (2018). http://www.bristol.ac.uk/sps/gettingthingschanged/. Accessed 30 Oct 2019.

Girli, A., Sarı, H. Y., Kırkım, G., \& Narin, S. (2016). University students' attitudes towards disability and their views on discrimination. International Journal of Developmental Disabilities, 62(2), 98-107.

Griful-Freixenet, J., Struyven, K., Verstichele, M., \& Andries, C. (2017). Higher education students with disabilities speaking out: Perceived barriers and opportunities of the universal design for learning framework. Disability \& Society, 32(10), 1627-1649.

Gustavsson, A. (2004). The role of theory in disability research - springboard or strait-jacket? Scandinavian Journal of Disability Research, 6(1), 55-70.

Hancock, P., \& Tyler, M. (2009). The management of everyday life. Basingstoke: Palgrave/Macmillan.

Hansen, N. (2008). A delicate balance: Chronic conditions and workspace. In D. Driedger \& M. Owen (Eds.), Dissonant disabilities: Women with chronic illnesses explore their lives (pp. 131-148). Ontario: Scholars' Press Inc..

Higher Education Statistics Agency. (2018). Higher Education Staff Statistics: UK, 2016/17. https://www.hesa. ac.uk/news/18-01-2018/sfr248-higher-education-staff-statistics. Accessed 30 Oct 2019.

Hui, A. (2017). Variation and the intersection of practices. In A. Hui, T. Schatzki, \& E. Shove (Eds.), The nexus of practices: Connections, constellations, practitioners (pp. 52-67). Oxford: Routledge.

Inckle, K. (2018). Unreasonable adjustments: The additional unpaid labour of academics with disabilities. Disability \& Society, 33(8), 1372-1376. 
Lourens, H., \& Swartz, L. (2016). Experiences of visually impaired students in higher education: Bodily perspectives on inclusive education. Disability \& Society, 31(2), 240-251.

Martin, B. R. (2016). What's happening to our universities? Prometheus, 34(1), 7-24.

Meekosha, H. (2011). Decolonising disability: Thinking and acting globally. Disability \& Society, 26(6), 667-682.

Mellifont, D., Smith-Merry, J., Dickinson, H., Llewellyn, G., Clifton, S., Ragen, J., Raffaele, M., \& Williamson, P. (2019). The ableism elephant in the academy: A study examining academia as informed by Australian scholars with lived experience. Disability \& Society. https://doi.org/10.1080/09687599.2019.1602510.

Mills, S., Trehan, K., \& Stewart, J. (2014). Academics in pursuit of the part-time doctorate: Pressures and support issues associated with the career development of business and management academics. Human Resource Development International, 17(4), 438-458.

Mutanga, O. (2018). Inclusion of students with disabilities in South African higher education. International Journal of Disability, Development and Education, 65(2), 229-242.

Oliver, M. (1990). The politics of disablement. Basingstoke: Macmillan.

Oliver, M. (1992). Changing the social relations of research production? Disability \& Society, 7(2), 101-114.

Raymaker, D. M. (2017). Reflections of a community-based participatory researcher from the intersection of disability advocacy, engineering, and the academy. Action Research, 15(3), 258-275.

Reason, P. (1994). Co-operative inquiry, participatory action research and action inquiry: Three approaches to participatory inquiry. In N. Denzin \& Y. Lincoln (Eds.), Handbook of qualitative research (pp. 324-339). London: Sage.

Reckwitz, A. (2002). Toward a theory of social practices: A development in culturalist theorizing. European Journal of Social Theory, 5(2), 243-263.

Roulstone, A., \& Williams, J. (2014). Being disabled, being a manager: "glass partitions" and conditional identities in the contemporary workplace. Disability \& Society, 29(1), 16-29.

Saldaña, J. (2015). The coding manual for qualitative researchers (3rd ed.). London: Sage.

Schatzki, T. (2001). Introduction: Practice theory. In T. Schatzki, K. Cetina, \& E. von Savigny (Eds.), The practice turn in contemporary theory (pp. 10-23). London: Taylor \& Francis.

Schatzki, T. (2017). Sayings, texts and discursive formations. In A. Hui, T. Schatzki, \& E. Shove (Eds.), The nexus of practices: Connections, constellations, practitioners (pp. 126-140). Oxford: Routledge.

Shakespeare, T. (2014). Disability rights and wrongs revisited. London: Routledge.

Shove, E., Pantzar, M., \& Watson, M. (2012). The dynamics of social practice: Everyday life and how it changes. London: Sage.

Swain, J., \& French, S. (2000). Towards an affirmation model of disability. Disability \& Society, 15(4), 569-582.

Taylor, A., \& Shallish, L. (2019). The logic of bio-meritocracy in the promotion of higher education equity. Disability \& Society. https://doi.org/10.1080/09687599.2019.1613962.

Thomas, C. (2004). How is disability understood? An examination of sociological approaches. Disability \& Society, 19(6), 569-583.

Titchkosky, T. (2008). To pee or not to pee? Ordinary talk about extraordinary exclusions in a university environment. Canadian Journal of Sociology, 33(1), 37-60.

Trahar, S. (Ed.). (2013). Contextualising narrative inquiry: Developing methodological approaches for local contexts. Oxford: Routledge.

Tudzi, E. P., Bugri, J. T., \& Danso, A. K. (2017). Human rights of students with disabilities in Ghana: Accessibility of the university built environment. Nordic Journal of Human Rights, 35(3), 275-294.

Wall, S. (2006). An autoethnography on learning about autoethnography. International Journal of Qualitative Methods, 5(2), 146-160.

Waterfield, B., Beagan, B., \& Weinberg, M. (2018). Disabled academics: A case study in Canadian universities. Disability \& Society, 33(3), 327-348.

Watson, M. (2017). Placing power in practice theory. In A. Hui, T. Schatzki, \& E. Shove (Eds.), The nexus of practices: Connections, constellations, practitioners (pp. 169-182). Oxford: Routledge.

Williams, J. (2011). What can disabled academics' career experiences offer to studies of organization? Doctoral thesis, Northumbria University.

Williams, V. (2019). 'Like us you mean?' Sensitive disability questions and peer research encounters. In K. K. Roulston (Ed.), Interactional studies of qualitative research interviews. Amsterdam: John Benjamins.

Williams, J., \& Mavin, S. (2015). Impairment effects as a career boundary: A case study of disabled academics. Studies in Higher Education, 40(1), 123-141.

Williams, V., Tarleton, B., Heslop, P., Porter, S., Sass, B., Blue, S., Merchant, W., \& Mason-Angelow, V. (2018). Understanding disabling barriers: a fruitful partnership between Disability Studies and social practices? Disability \& Society, 33(2), 157-174.

Publisher's note Springer Nature remains neutral with regard to jurisdictional claims in published maps and institutional affiliations. 